\title{
Synaptic Transmission between Individual Pyramidal Neurons of the Rat Visual Cortex in vitro
}

\author{
Adrian Mason, Andrew Nicoll, and Ken Stratford \\ University Laboratory of Physiology, Oxford OX1 3PT, U.K.
}

Synaptic transmission between pairs of neurons in layer $2 / 3$ of in vitro slices from the rat visual cortex was studied by dual intracellular recording. The intrinsic electrophysiological properties of these neurons suggested that they were pyramidal cells. More than $1 / 3$ of the total number of synaptically connected neurons were stained by intracellular iontophoresis of biocytin, and all had pyramidal morphology. Postsynaptic potentials (PSPs) were evoked by single action potentials (elicited by current injection) in presynaptic cells. Measurements of PSP latency, amplitude, and shape were made on spike-triggered averages. Forty-eight synaptic connections were found out of a possible total of 549, equivalent to a probability of about 0.09 . For these 48 connections, the distance between the 2 impalement sites ranged from 50 to $340 \mu \mathrm{m}$. All PSPs were depolarizing at rest $(-74 \pm 5 \mathrm{mV}$, mean \pm SD), and all 14 of the PSPs that were also recorded with the postsynaptic cell depolarized to around action potential threshold (about $-55 \mathrm{mV}$ ) remained depolarizing. PSPs had short latencies (1.2 $\pm 0.6 \mathrm{msec}$, mean \pm SD), suggesting that they were mediated by monosynaptic pathways. Peak amplitudes of the averaged PSPs varied widely (range, $0.05-$ $2.08 \mathrm{mV}$ ), but the majority were less than $0.5 \mathrm{mV}$. PSPs decayed exponentially with time constants that were correlated with, but slightly longer than, the membrane time constants of the postsynaptic cells measured using injected current pulses. Four cell pairs were connected reciprocally, and 6 examples of convergent input were found in which a single cell was postsynaptic to more than 1 presynaptic cell. Trialto-trial fluctuations in PSP amplitude were analyzed for $\mathbf{1 6}$ synaptic connections. The amplitude of the PSP evoked by a presynaptic action potential fluctuated more than could be accounted for by the background noise.

Pyramidal cells are the most abundant neuronal cell type in the neocortex (Feldman, 1984; Peters, 1987a). Although their role as output neurons has traditionally been emphasized, most pyramidal cells have numerous axon collaterals within their cortical area of origin (Feldman, 1984). Indeed, axon collaterals of pyramidal cells form the presynaptic elements for the majority of all synapses in the neocortex (Peters, 1987a). Typically, axon

\footnotetext{
Received July 2, 1990; accepted Aug. 20, 1990.

This work was supported by The Wellcome Trust (Grant 15932/1.5 to Colin Blakemore and Julian Jack), the Medical Research Council (Grant PG7900491 to Colin Blakemore), and the University of Oxford. A.N. is an MRC scholar. We are grateful to Sarah Bacon for help in preparing the illustrations and to John Mittell for assistance with electronics. We thank our colleagues, particularly Guy Major and Michael Hăusser, for helpful comments on the manuscript.

Correspondence should be addressed to Dr. Adrian Mason, University Department of Pharmacology, South Parks Road, Oxford OXI 3QT, UK.

Copyright (c) 1991 Society for Neuroscience $0270-6474 / 91 / 010072-13 \$ 03.00 / 0$
}

collaterals ramify both within the vicinity of the parent cell body and also at distances up to several millimeters away (Winfield et al., 1981; Gilbert and Wiesel, 1983; Feldman, 1984; Martin and Whitteridge, 1984; Peters and Kara, 1985; Ghosh and Porter, 1988). The axon collaterals give rise to asymmetric synaptic specializations, generally considered to be excitatory in function (Peters, 1987b), on postsynaptic neurons (Winfield et al., 1981; Feldman, 1984; Kisvárday et al., 1986; Gabbott et al., 1987; Elhanany and White, 1990). In many cases, the major postsynaptic targets of pyramidal-cell axon collaterals are other pyramidal cells (Kisvárday et al., 1986; Gabbott et al., 1987; Elhanany and White, 1990), though some pyramidal cells make a large proportion of their intracortical synapses with nonpyramidal neurons (McGuire et al., 1984; White and Keller, 1987).

Electrophysiological studies both in vivo (e.g., Stefanis and Jasper, 1964; Takahashi et al., 1967; Ferster and Lindström, 1985; Kang et al., 1988) and in vitro (e.g., Jones and Baughman, 1988; Komatsu et al., 1988; Sutor and Hablitz, 1989a,b; Thomson et al., 1988, 1989) have demonstrated the existence of excitatory connections between pyramidal neurons. Consistent with the evidence that the excitatory neurotransmitter in the neocortex is glutamate or aspartate (Baughman and Gilbert, 1981; Streit, 1984; Dori et al., 1989), such in vitro studies have also shown that synaptic transmission between pyramidal neurons is mediated by receptors for excitatory amino acids.

However, there have been few attempts to investigate the functional properties of connections between individual neocortical pyramidal neurons. The most direct way of doing this is to make simultaneous intracellular recordings from pairs of synaptically connected pyramidal neurons. Several groups have used dual intracellular recordings to investigate synaptic properties in the hippocampus (e.g., MacVicar and Dudek, 1980; Knowles and Schwartzkroin, 1981; Miles and Wong, 1986; Sayer et al., 1990). However, with the exception of a study on rat visual cortical neurons in dissociated cell culture (Huettner and Baughman, 1988), to our knowledge, there is no full account of the application of this technique to the neocortex. Excitation of presynaptic neurons by glutamate iontophoresis or focal extracellular electrical stimulation, combined with intracellular recording from postsynaptic neurons, has been used to investigate synaptic interactions in the motor (Kang et al., 1988), visual (Komatsu et al., 1988), and cingulate and sensorimotor cortex (Thomson et al., 1988, 1989). These methods, though technically somewhat simpler, suffer from a number of disadvantages. They do not allow identification of the presynaptic neurons by intracellular staining and are unlikely to detect reciprocal connections. Also, particularly for glutamate iontophoresis, the firing pattern of the presynaptic neuron cannot be precisely controlled, and more than 1 presynaptic neuron may be excited. 
We have used simultaneous intracellular recording from pairs of neurons to study synaptic connections between individual pyramidal neurons in layer $2 / 3$ of in vitro slices from rat visual cortex.

Preliminary results have been published in abstract form (Mason et al., 1989).

\section{Materials and Methods}

Slice preparation and maintenance. Twenty-one albino rats ( $20 \mathrm{Wistar}$, 1 Sprague-Dawley) of either sex, ranging in weight from 122 to $188 \mathrm{gm}$, were used in this study. Details of slice preparation and maintenance have been given previously (Larkman et al., 1988; Larkman and Mason, 1990). Briefly, the animal was anesthetized with halothane vapor (Fluothane, I.C.I.), then decapitated. Several $400-\mu \mathrm{m}$-thick coronal slices were cut from the visual cortex of 1 hemisphere using a vibrating microtome (Vibroslice, Campden Instruments). The slices were placed in an interface-type recording chamber at $34-35^{\circ} \mathrm{C}$. Artificial cerebrospinal fluid (ACSF) flowed around the lower parts of the slices at $0.1-0.2 \mathrm{ml} /$ min, and humidified gas $\left(95 \% \mathrm{O}_{2}, 5 \% \mathrm{CO}_{2}\right)$ was passed over the slices. Slices were left in the chamber for $2 \mathrm{hr}$ before intracellular impalements were attempted. The composition of the ACSF used throughout slice preparation and electrophysiological recording was (in $\mathrm{mM}$ ) $\mathrm{NaCl}, 124$; $\mathrm{KCl}, 2.3$ (3.3 in the first 6 experiments); $\mathrm{MgSO}_{4}, 1.0 ; \mathrm{KH}_{2} \mathrm{PO}_{4}, 1.3$ $\mathrm{CaCl}_{2}, 2.5 ; \mathrm{NaHCO}_{3}, 26$; and glucose, $10(\mathrm{pH}, 7.4)$.

Neuronal impalement and recording. Micropipettes were filled with a solution of $2 \mathrm{M}$ potassium methylsulfate and $5 \mathrm{~mm}$ potassium chloride. In 16 of the 21 experiments, they also contained 1-3\% biocytin (Sigma) for intracellular staining (Horikawa and Armstrong, 1988). DC resistances of the micropipettes, measured in ACSF, were 60-90 M 2 .

Although cortical layers were not visible in the slice, their positions were estimated with the aid of a calibrated eyepiece graticule in the stereomicroscope and reference to previous determinations of cortical layering (Peters and Kara, 1985; Peters et al., 1985). The first micropipette was advanced into layer $2 / 3$ until an impalement was obtained. After a few minutes to allow recovery from impalement damage, we required the neuron to have a stable resting potential more negative than $-60 \mathrm{mV}$ (without holding current) and to show overshooting action potentials in response to depolarizing current pulses. When an impalement meeting these criteria was obtained, the second micropipette was positioned on the surface of the slice within a circular region centered on the first micropipette and of a radius of approximately $250 \mu \mathrm{m}$. The second micropipette was then advanced into the slice until an impalement was obtained. The only criterion that we imposed upon this impalement was that single action potentials could be evoked reliably by depolarizing current pulses.

Using standard bridge-balance techniques, depolarizing current pulses (50-160 msec, 0.4-1.5 nA) were injected into the second cell at $2 \mathrm{~Hz}$. The amplitude of the current pulses was adjusted so that a single action potential was elicited by each pulse. We used signal-averaging software (sigAvg, Cambridge Electronic Design) and a combination of microcomputer (IBM PC-AT) and laboratory interface (CED 1401, Cambridge Electronic Design) to display an accumulating average of the intracellular voltage record of the first cell, with the averager triggered by the evoked action potentials in the second cell. If no postsynaptic potential (PSP) was visible after 50-100 sweeps, another neuron was sought with the second micropipette and the process repeated. However, if the second impalement also met the resting and action potential criteria applied to the first impalement, the procedure was reversed, and we looked for a PSP in the second cell as a result of action potentials evoked in the first cell. If the pair of cells was not synaptically connected in either direction, the better of the 2 impalements was kept and another neuron sought with the remaining micropipette. We estimate that only PSPs whose averaged amplitude was greater than about $0.03 \mathrm{mV}$ would have been detected by our procedures.

When a synaptic connection was detected, the intracellular voltage records of both cells were recorded on tape (Racal Store 4DS; bandwidth, $0-5 \mathrm{kHz} \pm 0.5 \mathrm{~dB}$ ), and the suprathreshold depolarizing current pulses in the presynaptic cell were continued. In each sweep, we also injected a small $(0.03-0.1 \mathrm{nA})$ depolarizing current pulse (duration, $140 \mathrm{msec}$ ) into the postsynaptic cell. These pulses were used to measure apparent input resistance and membrane time constant (see below). We continued recording until at least several hundred sweeps had been acquired or until an impalement was lost. In some cases, we also recorded data directly to computer disk, using a digitization rate of $10 \mathrm{kHz}$ per channel.
In some cases, after electrophysiological recording, we attempted to iontophorese biocytin (Sigma) into one or both neurons using hyperpolarizing pulses $(0.5 \mathrm{nA}, 200 \mathrm{msec})$ delivered at $2 \mathrm{~Hz}$ for $10-15 \mathrm{~min}$. Using the calibrated eyepiece graticule of the stereomicroscope, we measured the distance of the 2 micropipette entry points from the pia and from each other. This latter figure, together with the depths of the micropipette tips below the slice surface and estimates of the angles between the micropipettes and the slice surface, was used to calculate the approximate separation of the micropipette tips within the slice. After the measurements had been made, both micropipettes were usually withdrawn. However, in a few cases, the impalement of the postsynaptic cell was maintained, and additional cells synaptically connected to it were sought with the other micropipette. Also, in some cases, extracellular controls were performed by withdrawing the micropipette to just outside the postsynaptic cell, then evoking action potentials in the presynaptic cell with pulses of the same strength and duration as those used during recording of the synaptic potential.

One difficulty of using 2 intracellular micropipettes in close proximity is the capacitative coupling that occurs between them. The particular problem in this study was the generation of a spikelike potential in the postsynaptic-cell recording channel by an action potential in the presynaptic-cell channel (Miles and Wong, 1986). This transient tended to obscure the onset of the synaptic potential, particularly when the latency was short. We were able to reduce greatly the size of this artifact with the "Cx comp" facility on the micropipette amplifier (Axoprobe-1A, Axon Instruments). This circuitry operates by injecting an adjustable, compensating current into the driven shield of one channel derived from the voltage in the other channel. It was necessary to modify the circuit to allow it to operate on either channel, and to reduce its gain in order to provide more precise control over artifact cancellation. Four synaptic connections from early experiments were recorded without the benefit of Cx comp. In these cases, the spike-coupling artifact was minimized (after the experiment) by subtracting a scaled, differentiated version of the presynaptic record from the postsynaptic record (Miles and Wong, 1986).

Flectrophysiological data analysis. For latency, amplitude, and shape analysis, the individual PSPs recorded on tape were digitized at $10 \mathrm{kHz}$ and averaged, with the averager triggered on a point half-way up the rising phase of the presynaptic-cell action potential. All subsequent measurements were made on the averaged PSP. The number of sweeps averaged ranged from 50 to 2447 (usually 100-500). Apparent input resistance of the postsynaptic cells was measured as the voltage deflection (averaged) just before the end of the depolarizing current pulse, divided by the amplitude of the current pulse. The membrane time constant was measured from the voltage decay (averaged) following the same current pulse. The voltage decay was plotted semilogarithmically, and the time constant was taken from the slope of a straight line fitted selectively (by linear regression) to a region of the plot. The region was chosen to exclude the early period of decay, which reflects redistribution of charge over the neuron (Rall, 1969). Time constants for the decay of PSPs were obtained in a similar manner. For amplitude fluctuation analysis, we selected synaptic connections for which more than 1000 sweeps were available. If they had not been recorded directly to disk during the experiment, the individual sweeps were replayed from tape, digitized at $10 \mathrm{kHz}$, and stored on disk. Unless otherwise stated, results are given as the mean $\pm \mathrm{SD}$, with the number of observations in parentheses.

Histology. With some modifications, we followed the biocytin reaction method of Horikawa and Armstrong (1988). Within $10 \mathrm{~min}$ of iontophoresing biocytin, the slice was fixed overnight in $2.5 \%$ glutaraldehyde and $2 \%$ paraformaldehyde. The fixative, and all other aqueous solutions, were made in $0.1 \mathrm{~m}$ phosphate buffer (PB) at $\mathrm{pH} 7.4$. After rinsing in $\mathrm{PB}$, the slice was resliced at a thickness of $60 \mu \mathrm{m}$ on a vibrating microtome (Vibroslice, Campden Instruments). After a 1-hr detergent treatment in $1 \%$ Triton-X100, the slices were incubated in HRP conjugated to avidin (HRP-A; Vector Labs) at a dilution of $1: 200$ in $0.5 \%$ Triton-X100 for $2 \mathrm{hr}$. The slices werc rinsed thoroughly in PB and transferred to a $0.16 \%$ solution of Hanker-Yates reagent (Sigma) for 15 min. Hydrogen peroxide solution was added to a final concentration of approximately $0.004 \%$ and the reaction monitored under a stereomicroscope. When the injected cells(s) had become sufficiently dark (about 5-10 min), the reaction was stopped by rinsing with PB. Slices were osmicated in $0.25-0.5 \%$ osmium tetroxide solution for $10-15 \mathrm{~min}$, then rinsed in PB. After dehydration in graded ethanols, slices were mounted in resin on microscope slides and coverslipped. Selected neurons were reconstructed from camera lucida drawings of individual $60-\mu \mathrm{m}$ sections 
Figure 1. Typical PSP and extracellular control. $A$, Simultaneous intracellular record (average of 1057 sweeps) from 2 neurons in layer $2 / 3$. A PSP was produced in one cell (upper trace) by single action potentials in the other cell of the pair (lower trace). Action potentials were evoked by long depolarizing current pulses (not shown) delivered at $2 \mathrm{~Hz}$. B, Extracellular control (average of 117 sweeps). The micropipette that had been in the postsynaptic cell was withdrawn to a position in the extracellular space just outside the cell (upper trace). Action potentials in the presynaptic cell (lower trace) evoked only a spike-coupling artifact in the $u p$ per trace. The upper trace in $B$ is noisier than in $A$ because fewer sweeps were averaged. Calibration bars apply to both $A$ and $B$.
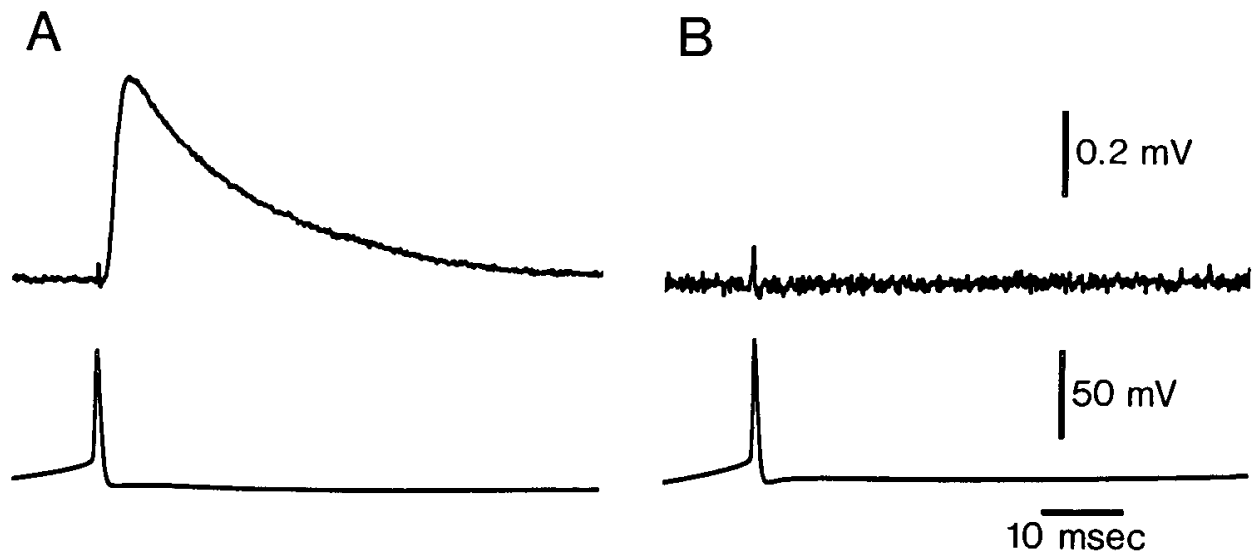

made at an overall magnification of $1000 \times$ (objective, $100 \times$; numerical aperture, 1.4).

\section{Results}

\section{Electrophysiological properties of neurons}

All impalement sites were between 200 and $650 \mu \mathrm{m}$ from the pia, a region that corresponds, in the rat visual cortex, to layer 2/3 (Peters and Kara, 1985; Peters et al., 1985). PSPs were recorded in 39 different neurons. All of these postsynaptic cells displayed action-potential shapes characteristic of neocortical pyramidal neurons (McCormick et al., 1985). They had resting membrane potentials of $-74 \pm 5 \mathrm{mV}$ (36), apparent input resistances of $40 \pm 15 \mathrm{M} \Omega(37)$, and membrane time constants of $13.2 \pm 4.0 \mathrm{msec}(37)$. These values are in good agreement with those obtained in a previous study of layer $2 / 3$ of the rat visual cortex in which the identity of the pyramidal neurons was confirmed by intracellular staining with HRP (Mason and Larkman, 1990). We did occasionally encounter neurons that had action potentials of shorter duration and faster firing rates on impalement, and it is likely that these were nonpyramidal neurons (McCormick et al., 1985). The 48 presynaptic cells (i.e., neurons in which action potentials elicited PSPs in the other neuron of a pair) also had action-potential shapes characteristic of pyramidal neurons. The resting membrane potentials of the presynaptic cells were $-65 \pm 12 \mathrm{mV}(43)$. This value is relatively low because we did not impose a minimum acceptable value for the presynaptic cell impalements, and some cells had resting potentials more positive than the $-60-\mathrm{mV}$ criterion level for postsynaptic cells. We did not measure the apparent input resistance or time constant of the presynaptic cells.

\section{Latency, shape, and amplitude of PSPs}

We tested 375 cell pairs for synaptic connections. (A cell pair is defined here by one or both of its member cells being different from those of any other cell pair.) One hundred seventy-four cell pairs were tested in both directions, and 201 cell pairs were tested in 1 direction only, yielding a total of 549 possible synaptic connections. Forty-eight connections were found. For these 48 connections, the distance between the 2 impalement sites ranged from 50 to $340 \mu \mathrm{m}$, with a mean of $140 \mu \mathrm{m}$.

A typical averaged record is shown in Figure $1 A$. All PSPs were depolarizing. The membrane potentials at which the PSPs were recorded ranged from -64 to $-83 \mathrm{mV}$ for different postsynaptic neurons. In 14 cases, we also recorded PSPs with the postsynaptic neuron depolarized to around action potential threshold (about $-55 \mathrm{mV}$ ) using injected current pulses. All of these PSPs remained depolarizing, and no hyperpolarizing components were revealed. Extracellular controls $(n=8)$ demonstrated that only a spike-coupling artifact (reduced, but usually not eliminated by the use of Cx comp; see Materials and Methods) remained when the micropipette that had been in the postsynaptic cell was withdrawn to a position just outside it (Fig. $1 B)$. A similar artifact remained when the micropipette was removed completely from the slice and positioned in the ACSF, proving that an extracellular field potential was not responsible.

On 3 occasions during the course of this study, we apparently impaled the same neuron with both micropipettes. Action potentials and subthreshold membrane polarizations, evoked by current injection through either micropipette, were synchronous in both channels. Although we think the most likely explanation is that both micropipettes were in the same neuron, we cannot exclude the possibility that we were recording from separate neurons that were strongly electrically coupled. We saw no evidence of electrical coupling between any of the cell pairs in which PSPs were recorded, but our experiments were not designed specifically to test for its presence, and very weak coupling may have gone undetected. Electrical synaptic transmission occurs in several regions of the mammalian nervous system (Bennett, 1977), and there is some evidence for its existence in the neocortex (Sloper, 1972; Connors et al., 1983; Peters, 1987b).

Latency, amplitude, and shape data for all of the averaged PSPs are summarized in Figure 2. The majority of PSPs had latencies less than $2 \mathrm{msec}$. There was no correlation between latency and the separation of the micropipette tips within the slice. Although the majority of averaged PSPs had amplitudes less than $0.5 \mathrm{mV}$, there was wide variation. The largest PSP $(2.08 \mathrm{mV})$ was approximately 40 times larger than the smallest $(0.05 \mathrm{mV})$. There was no correlation between PSP amplitude and the separation of the micropipette tips, their depths within the slice, or their distances from the pia; neither was PSP amplitude correlated with the membrane potential, apparent input resistance, or time constant of the postsynaptic neuron.

Most PSPs appeared to have smooth rising phases, but in 3 cases, there was an obvious "notch" on the rising phasc. In 1 

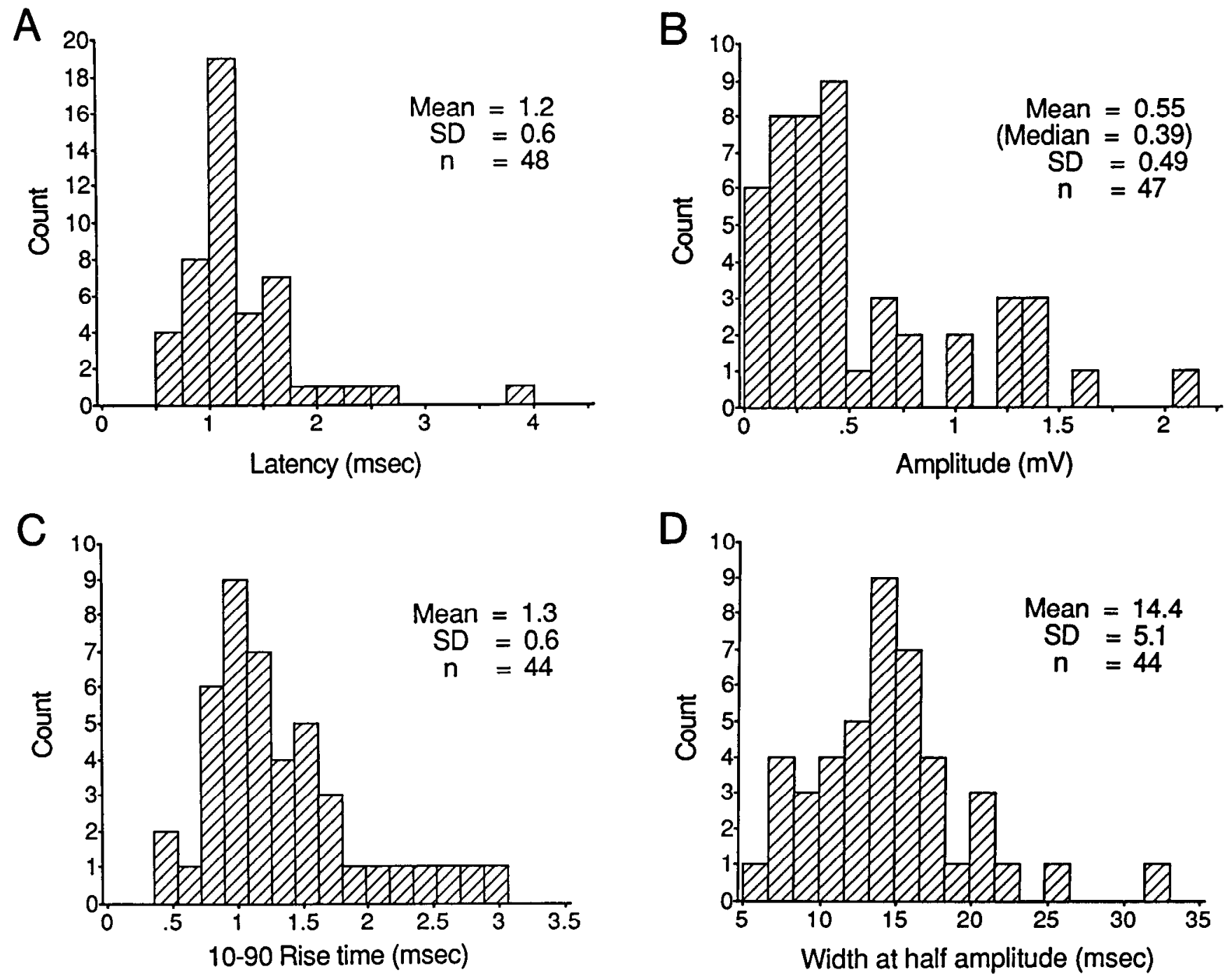

Figure 2. Summary of latency, shape, and amplitude for all averaged PSPs. $A$, Latency was measured from the midpoint of the upstroke of the presynaptic action potential to the first digitized point of the PSP that was clearly above the baseline. $B$, Amplitude was measured from the baseline (averaged over an interval of 5-20 msec) to the peak of the PSP (averaged over an interval of $0.5-2.0 \mathrm{msec}$ ). $C$, The $10-90 \%$ rise time was measured as the time difference between 2 points on the rising phase of the PSP corresponding to $10 \%$ and $90 \%$ of the peak amplitude. $D$, Width at half amplitude was measured as the time difference between points on the rising phase and falling phase of the PSP corresponding to $50 \%$ of the peak amplitude. Three PSPs had obvious "notches" on their rising phases and were excluded from rise time and width measurements.

of these 3 cases, notches could be seen on individual sweeps of the PSP, with no averaging. Therefore, for this synaptic potential, at least, the notch was not an artifact caused by, for example, the averager being triggered at a different point on the presynaptic action-potential waveform in some sweeps. Unfortunately, the signal-to-noise ratio for the other 2 PSPs was too small to determine whether or not individual sweeps had notches on their rising phases.

There was a correlation between the widths at half amplitude and the $10-90 \%$ rise times of the averaged PSPs. A shape index plot, with these values normalized by the membrane time constant, is shown in Figure 3. The correlation is highly significant (Kendall coefficient of rank correlation $=0.39, p<0.001$ ), but the plot shows considerable scatter. There was no correlation between either $10-90 \%$ rise time or width at half amplitude and PSP amplitude.

For most PSPs, much of the falling phase conformed to single exponential decay (Fig. 4). We determined a time constant of synaptic potential decay for each of the 36 PSPs that had an adequate signal-to-noise ratio and no obvious notch on the rising phase and for which a measurement of the postsynaptic cell membrane time constant was also available. Only 4 of the 36 PSPs had time constants of decay shorter than the membrane time constants of the cells in which they were recorded, and, on average, the time constant of PSP decay was 1.3 times longer than the membrane time constant (Fig. 4). However, there was a good correlation between the time constant of PSP decay and the membrane time constant of the cell in which the PSP was recorded (Fig. 5). Although there are 2 or 3 outlying points, the correlation is highly significant (Kendall coefficient of rank correlation $=0.61, p<0.001$ ). There was also a good correlation between the width at half amplitude of the PSP and the cell membrane time constant (data not shown).

\section{Multiple PSPs recorded in the same postsynaptic neuron}

In 6 cases, we found more than 1 cell that was presynaptic to a single postsynaptic cell. Some of the properties of these PSPs are given in Table 1. All PSPs of different origin recorded in a 


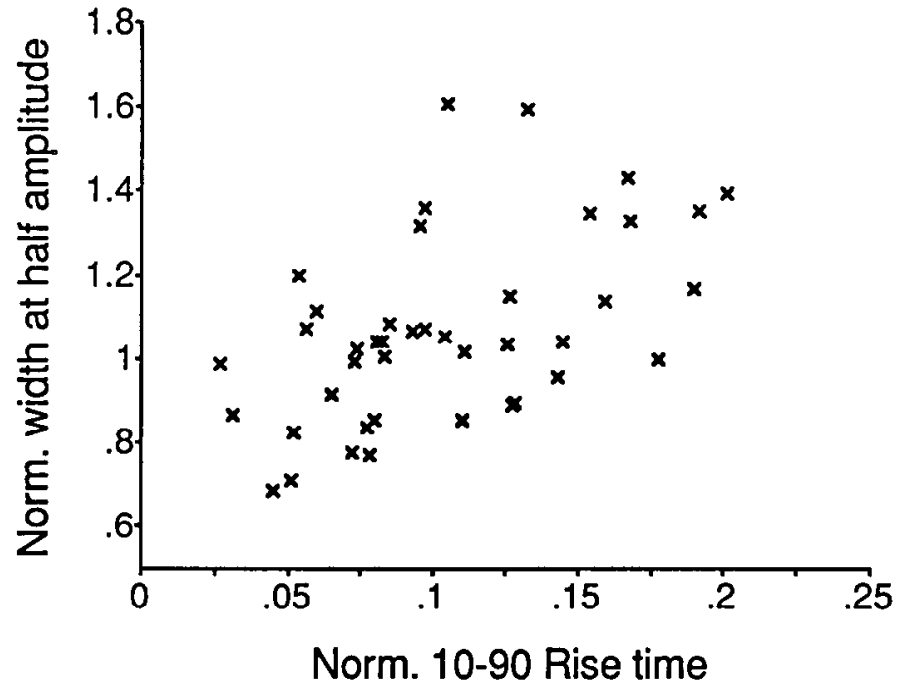

Figure 3. Shape index plot. Each point represents 1 averaged PSP. For each PSP, the width at half amplitude and $10-90 \%$ rise time were normalized by dividing by the membrane time constant of the postsynaptic cell.

single postsynaptic cell appeared to have similar decay time constants and widths at half amplitude. However, their 10-90\% rise times and amplitudes seemed as different as those of PSPs recorded in different postsynaptic cells. A 1-way analysis of variance (ANOVA) confirmed these impressions (see Table 1 note), with the exception that the similarity of widths at half amplitude was not significant.

The shape indices of these PSPs were compared with the shape
Table 1. PSPs of different origin recorded in single postsynaptic cells

\begin{tabular}{lllll}
$\begin{array}{l}\text { Post- } \\
\text { synaptic } \\
\text { cell }\end{array}$ & $\begin{array}{l}\text { PSP } \\
\text { amplitude } \\
\text { (mV) }\end{array}$ & $\begin{array}{l}\text { PSP } \\
10-90 \% \\
\text { rise time } \\
\text { (msec) }\end{array}$ & $\begin{array}{l}\text { PSP width } \\
\text { at half } \\
\text { amplitude } \\
\text { (msec) }\end{array}$ & $\begin{array}{l}\text { PSP decay } \\
\text { time } \\
\text { constant } \\
\text { (msec) }\end{array}$ \\
\hline 1 & 0.80 & 1.63 & 19.7 & 23.2 \\
& 1.28 & 1.03 & 14.3 & 20.3 \\
2 & 2.08 & 1.21 & 8.1 & 12.3 \\
& 0.10 & 1.67 & 14.3 & 15.4 \\
3 & 0.15 & 0.41 & 15.2 & 17.5 \\
& 0.42 & 2.01 & 14.5 & 15.3 \\
& 0.36 & 0.79 & 14.9 & 18.0 \\
4 & 0.34 & 1.62 & 14.7 & 16.7 \\
& 1.56 & 1.93 & 15.3 & 15.8 \\
& 0.59 & 0.82 & 11.1 & 14.2 \\
5 & 0.24 & 2.29 & 20.7 & 18.9 \\
& 1.28 & 1.45 & 15.8 & 18.7 \\
ANOVA & $p=0.74$ & $p=0.73$ & $p=0.21$ & $p<0.01$
\end{tabular}

One of the 6 cells in which multiple PSPs were recorded is not included in this table. Time constant and apparent input resistance measurements indicated that the properties of this cell had changed in the interval between recording the 2 different PSPs. For each of the tabulated PSP attributes, a 1-way ANOVA was performed to test the null hypothesis that any similarity between PSPs recorded in the same postsynaptic cell was due to chance alone. The $p$ values show that the null hypothesis is rejected only for the PSP decay time constant.

indices of the entire sample. In some cases, PSPs of different origin recorded in a single postsynaptic cell had shape indices that spanned a large part of the shape index plot (data not shown).
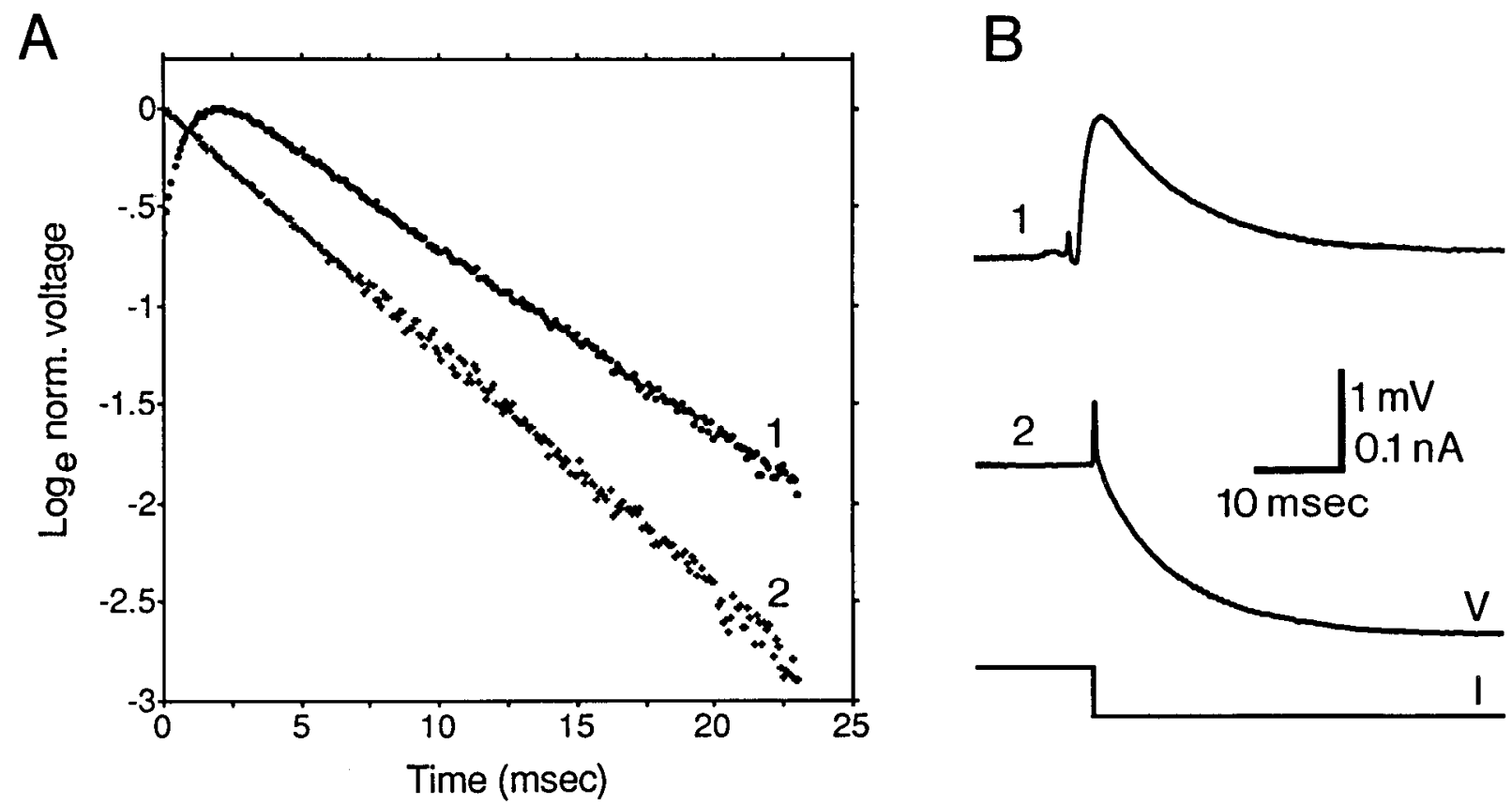

Figure 4. PSP decay. $A$, Semilogarithmic plot of PSP decay (curve $l$ ) and the decay after an injected depolarizing current pulse (curve 2) recorded in the same cell. To facilitate comparison of the 2 decays, voltages were normalized by their peak amplitudes before taking logarithms. Zero time was taken as $1 \mathrm{msec}$ after the end of the current pulse for the pulse decay and half way up the rising phase for the PSP. The time constants of PSP decay and pulse decay were 10.6 and $8.3 \mathrm{msec}$, respectively. $B$, Voltage traces (upper and middle) from which the curves in $A$ were derived, together with the current record (lower) for the pulse [averages of 388 sweeps (PSP) and 541 sweeps (pulse)]. Time calibration bar applies to all 3 traces, voltage calibration bar to upper and middle traces. 


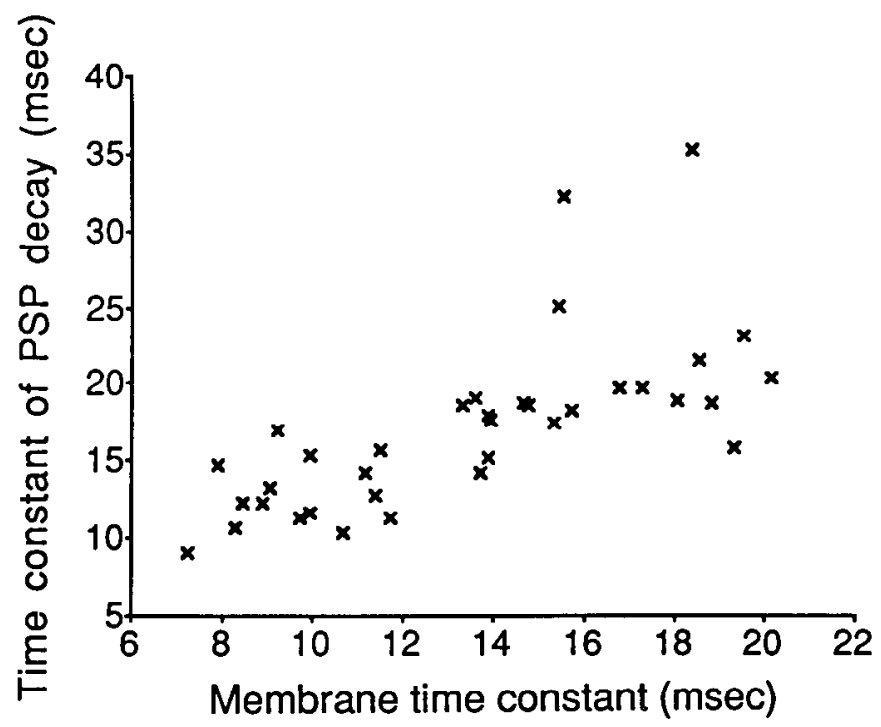

Figure 5. Correlation hetween time constant of PSP decay and membrane time constant.

\section{Reciprocally connected neurons}

Of the 174 cell pairs in which we were able to look for synaptic connections in both directions, we found 4 pairs of neurons for which action potentials in either cell evoked depolarizing PSPs in the other cell (Table 2, Fig. 6). These cases were easily distinguishable from those in which both micropipettes impaled the same cell, and there was no evidence of electrical coupling. The latencies, amplitudes, $10-90 \%$ rise times, and widths at half amplitude of thesc PSPs werc similar to those of the whole sample of PSPs. Neither was there anything exceptional about the placement of the 2 micropipettes in these cases; the separation of the micropipette tips ranged from 80 to $230 \mu \mathrm{m}$. In one case, intracellular injection of biocytin confirmed that both cells of a reciprocally coupled pair were pyramidal in form. In view of this evidence, it seems likely that each cell of a pair made a monosynaptic excitatory connection with the other member of the pair.

\section{Morphology of neurons}

In the majority of experiments, the micropipettes contained biocytin for intracellular staining of the impaled neurons. Twen-
Table 2. Reciprocally connected pairs of neurons

\begin{tabular}{llll} 
Cell pair & $\begin{array}{l}\text { Micropipette } \\
\text { separation } \\
(\mu \mathrm{m})\end{array}$ & $\begin{array}{l}\text { PSP latency } \\
(\mathrm{msec})\end{array}$ & $\begin{array}{l}\text { PSP } \\
\text { amplitude } \\
(\mathrm{mV})\end{array}$ \\
\hline 1 & 80 & 1.1 & 0.15 \\
& & 0.8 & 0.39 \\
2 & 105 & 0.6 & 0.27 \\
& & 0.8 & 1.38 \\
3 & 233 & 1.0 & 0.48 \\
4 & \multirow{2}{*}{185} & 1.7 & 0.18 \\
& & 1.2 & 1.07 \\
& & 1.7 & 0.44 \\
\hline
\end{tabular}

ty-eight of the 79 different presynaptic or postsynaptic cells impaled in this study were stained successfully, and all had pyramidal morphology (Fig. 7). In 9 cases, including 1 reciprocally coupled pair, both the presynaptic and postsynaptic neurons were stained. The appearance of the stained cells agreed with previous descriptions of the morphology of pyramidal cells in layer $2 / 3$ of the rat visual cortex from Golgi impregnation (Peters and Kara, 1985) or intracellular HRP injection (Larkman et al., 1988; Larkman and Mason, 1990). Local axon collaterals would overlap both the apical and the basal dendrites of other pyramidal neurons nearby (see Fig. 7), allowing synaptic contacts from a single presynaptic cell to be distributed widely over the dendritic arbor of a postsynaptic neuron. Unfortunately, the axon collaterals of presynaptic neurons were more poorly stained than those of postsynaptic neurons, probably because the impalements of presynaptic cells were usually of lower quality and shorter duration. We were therefore unable to trace presynaptic axon collaterals to sites of putative synaptic contact with the dendrites of postsynaptic neurons.

Although we assume that the morphological substrates of the PSPs recorded in this study were synapses made by local axon collaterals of the presynaptic neuron onto dendrites of the postsynaptic neuron, it must be pointed out that the dendritic arbors of the presynaptic and postsynaptic cells probably overlapped in many cases, allowing the possibility that the PSPs were mediated by dendrodendritic synapses. Such synapses have been described in several parts of the mammalian CNS (Reese and Shepherd, 1972), including the neocortex (Sloper, 1971).
A
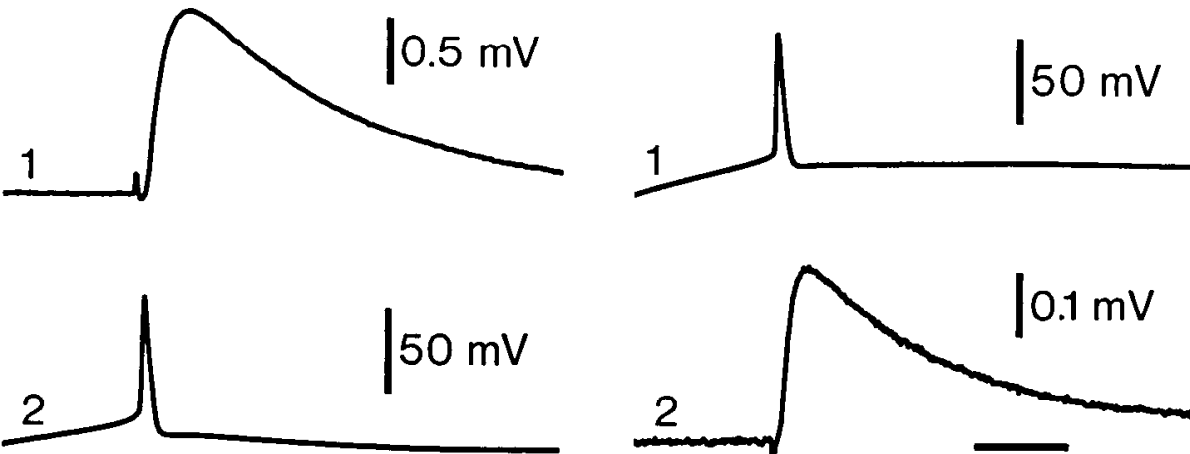

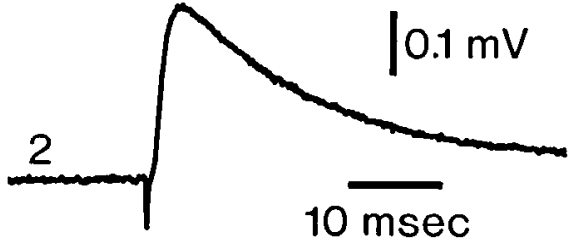

Figure 6. Reciprocal connection. $A$, Action potentials evoked by long depolarizing current pulses in cell 2 (lower trace) produced PSPs in cell 1 (upper trace; average of 907 sweeps). $B$, Action potentials evoked in cell 1 (upper trace) produced PSPs in cell 2 (lower trace; average of 2447 sweeps). Note the different voltage scales for the postsynaptic traces. 
pia

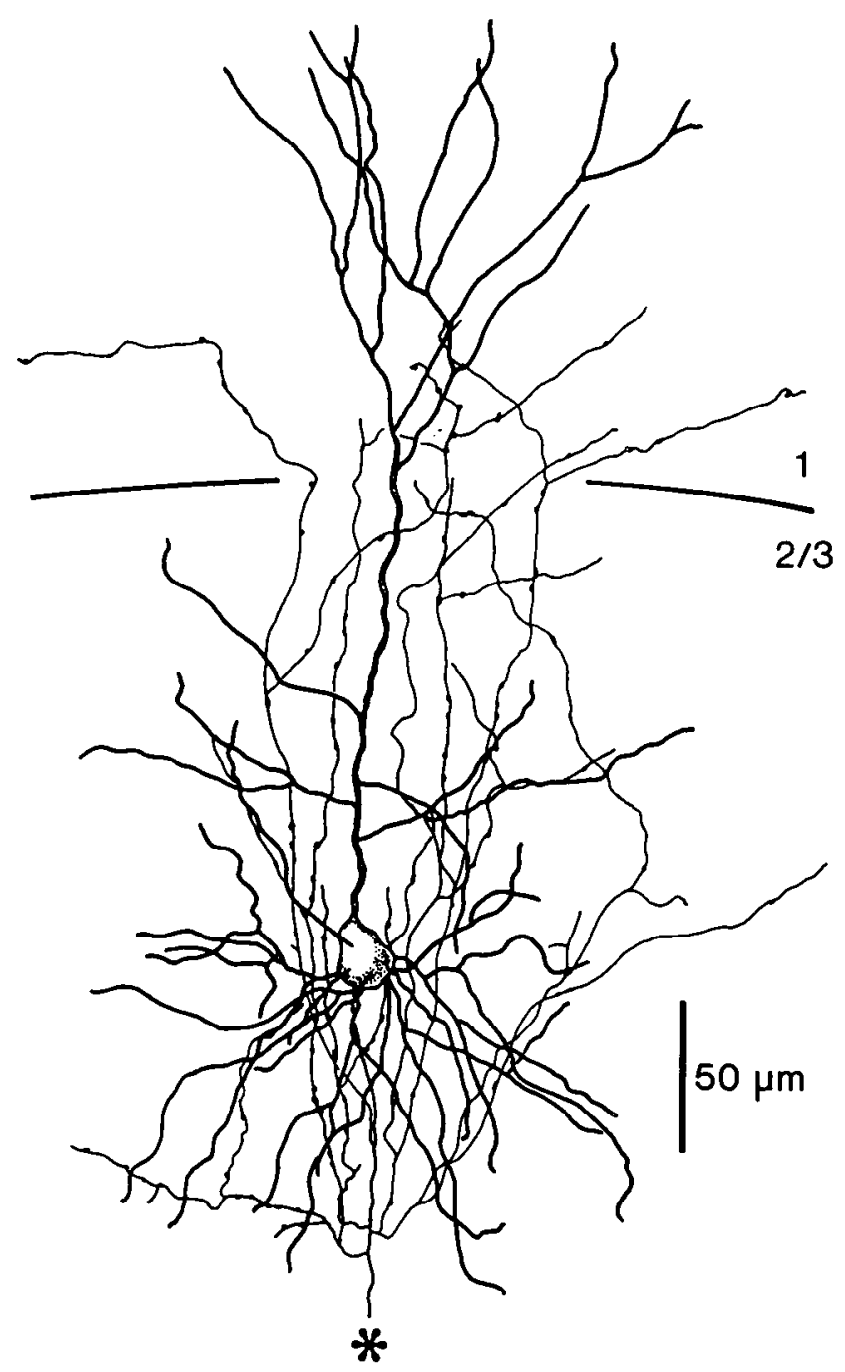

Figure 7. Camera lucida drawing of biocytin-filled pyramidal neuron in layer 2/3, from which 3 different PSPs were recorded (cell 3 in Table 1). The axon arbor is drawn in thinner line and axonal boutons are indicated by dots. The major descending axon could be traced beyond the asterisk but is not shown here. The positions of the pia and the boundary between layer $l$ and layer $2 / 3$ are indicated by lines.

\section{Fluctuations in PSP amplitude}

During acquisition and averaging of PSPs, it became apparent that their amplitudes fluctuated from sweep to sweep, despite the presynaptic neuron firing a single action potential reliably on each sweep. However, because the background noise levels were relatively high compared to the amplitudes of most PSPs, it was usually impossible, by simple inspection of individual sweeps, to exclude the possibility that the fluctuations were due to random changes in the background noise. (The background noise consisted not only of noise due to the micropipette and associated electronics, but also of "spontaneous" synaptic potentials.) A more objective approach was required that allowed independent estimation of the noise variation and of the noisecontaminated PSP amplitude fluctuations. For this analysis, we selected only the 16 synaptic connections for which at least 1000
Table 3. F test of PSP amplitude fluctuations

\begin{tabular}{rll} 
PSP & $\begin{array}{l}\text { Number of } \begin{array}{l}\text { Number of } 100 \text {-sweep } \\
\text { cpochs }\end{array} \\
\text { epochs where } \\
F \geq 1.48\end{array}$ \\
\hline 1 & 40 & 40 \\
2 & 30 & 30 \\
3 & 38 & 38 \\
4 & 10 & 10 \\
5 & 20 & 13 \\
6 & 38 & 37 \\
7 & 20 & 7 \\
8 & 20 & 5 \\
9 & 19 & 10 \\
10 & 20 & 10 \\
11 & 13 & 13 \\
12 & 10 & 10 \\
13 & 19 & 16 \\
14 & 19 & 18 \\
15 & 19 & 13 \\
16 & 11 & 5
\end{tabular}

The records for each PSP for which at least 1000 sweeps were available were divided up into consecutive epochs of 100 sweeps. $F$ tests of variance ratios were performed on each epoch (see text). $F$ values were calculated as $\left(\mathrm{SD}_{\mathrm{PSP}}+\right.$ noise ${ }^{2} /$ $\left(\mathrm{SD}_{\text {ise }}\right)^{2}$. The null hypothesis was that the noise-contaminated PSP sample distribution came from a population whose variance was no larger than that of the population from which the noise sample distribution was drawn. An $F$ value equal to or greater than 1.48 leads to rejection of the null hypothesis at the $p<0.05$ level (1-tailed test).

sweeps were available. The method (Jack et al., 1981) is shown for a single synaptic connection in Figure 8. For illustrative purposes, we have chosen a PSP whose amplitude was sufficiently large compared to the noise level for it to be fairly obvious, from simple inspection of individual sweeps, that the amplitude fluctuations cannot be accounted for by variations in background noise (Fig. 8A).

For each individual sweep, the postsynaptic cell voltage was averaged over each of 4 equal-length periods $(1-5 \mathrm{msec})$, separated by equal intervals $(2.5-6.5 \mathrm{msec})$. The first 2 periods both preceded the PSP, and the difference between their average voltage values was calculated for each sweep. The complete set of those differences ( 1 for each sweep) provided the noise sample distribution. Similarly, the sample distribution of the noisecontaminated PSP was obtained from the set of differences between the average voltage of a period just before the PSP and the average voltage of a period encompassing the peak of the PSP (Fig. 8C). An $F$ test of variance ratio should then have made it possible to test the null hypothesis that the noise-contaminated PSP sample distribution came from a population whose variance was no larger than that of the population from which the noise sample distribution was drawn; that is, the fluctuations in noise-contaminated PSP amplitude were due to variations in background noise. However, there was an additional problem. When sequential epochs of 100 records were averaged and plotted against time, most synaptic connections showed considerable changes in mean PSP amplitude over time (e.g., Fig. 8D). To avoid complications due to this long-term drift, we performed an $F$ test of variance ratio separately for each 100-sweep epoch (Fig. 8D, Table 3). For 8 of the synaptic connections, the null hypothesis could be rejected (at the $p<$ 0.05 level) for over $90 \%$ of the 100 -sweep epochs, and all 16 synaptic connections had at least some 100 -sweep epochs for 

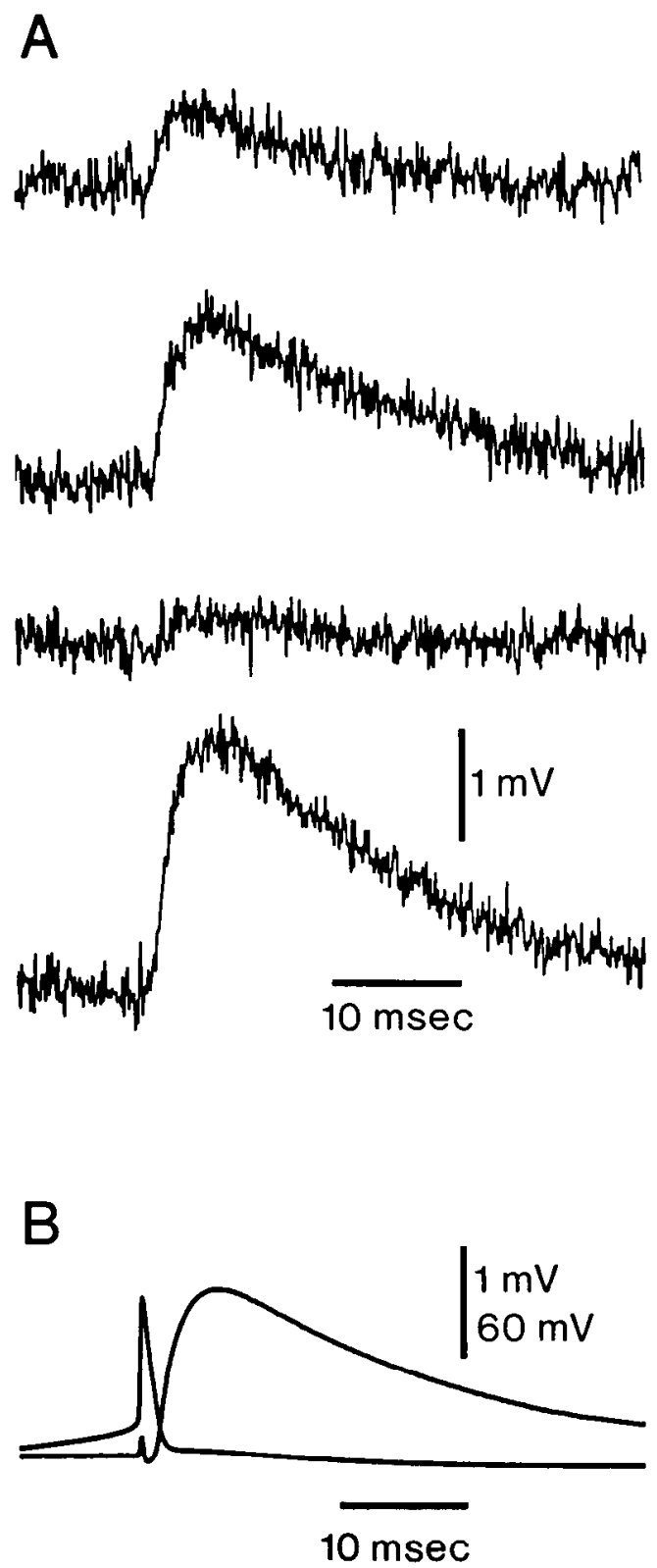
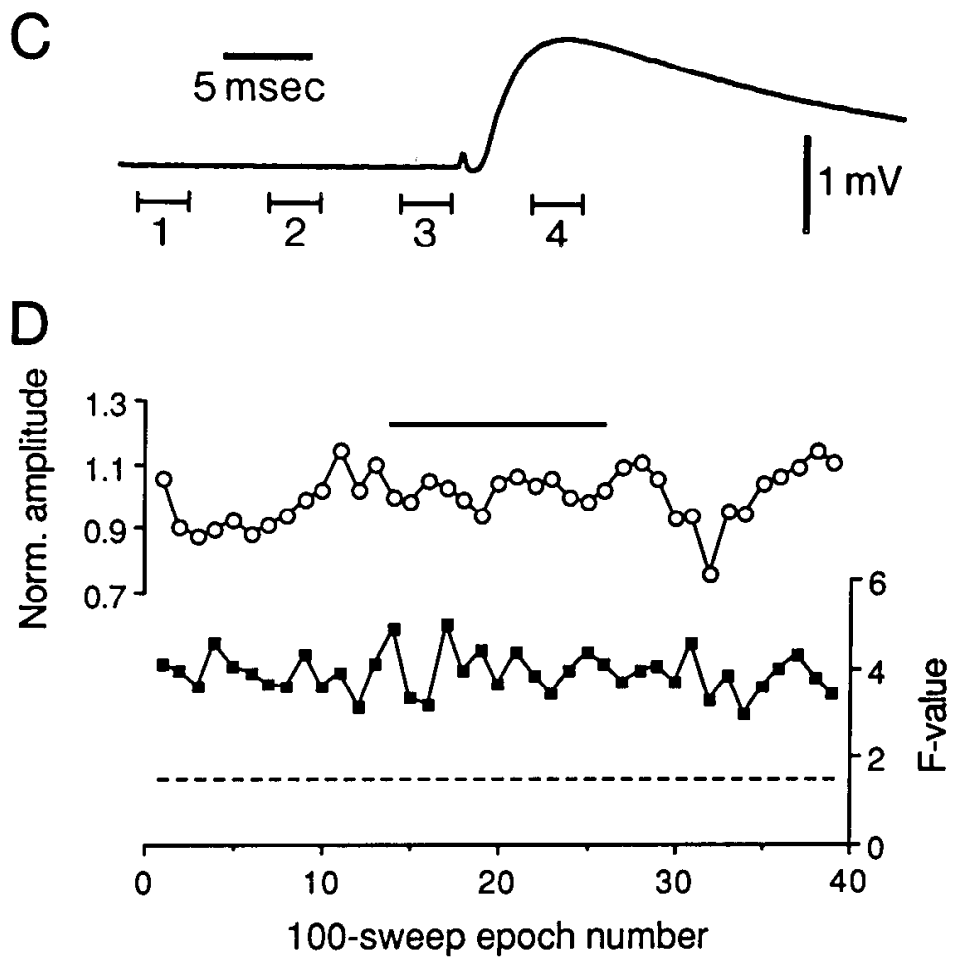

E

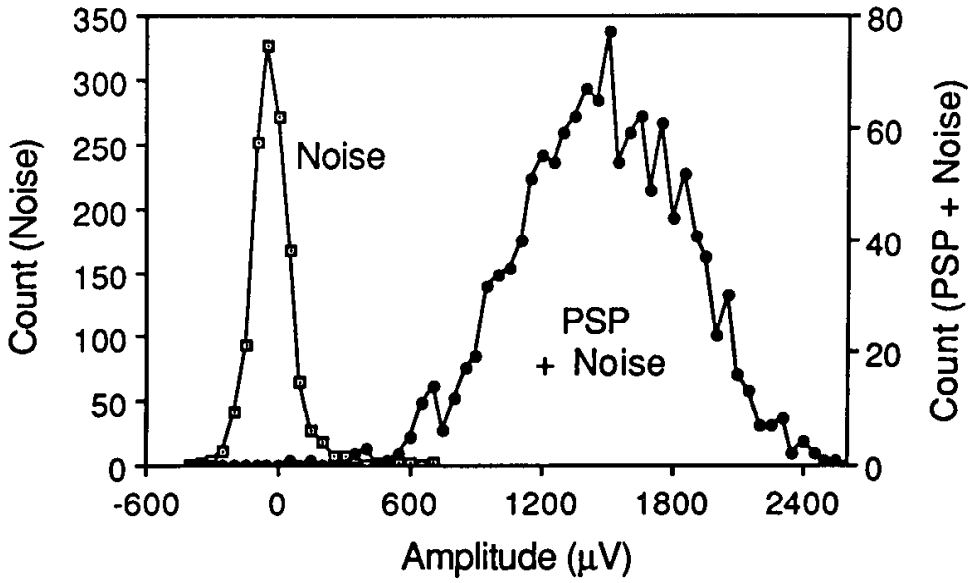

Figure 8. Fluctuations in PSP amplitude. All data are from the same synaptic connection (PSP 3 in Tables 3, 4). A, Four individual sweeps. The presynaptic cell fired a single action potential on each sweep (not shown). Calibration bars apply to all 4 traces; compare with $B$, which shows the average of 2008 sweeps (at the same time and voltage scale), together with the presynaptic record. $C$, Averaged PSP illustrating the measurement periods applied to individual sweeps to construct the sample distributions of the noise (periods 1 and 2) and of the noise-contaminated PSP (periods 3 and 4). D, top, Drift in PSP amplitude over time. Each point (circles) represents the noise-contaminated PSP amplitude averaged over 100 sweeps. Values were normalized by the PSP amplitude averaged over all the sweeps. The horizontal bar above the curve indicates the "stationary" region (see text) used to construct the amplitude distribution in $E . D$, bottom, $F$ test of variance ratio for noise and noise-contaminated PSP. Each point (squares) represents the $F$ value for 1 100-sweep epoch. For this synaptic connection, all $F$ values were greater than 1.48 (dashed line), indicating that the variance of the noise-contaminated PSP was significantly greater $(p<0.05)$ than the variance of the noise alone (see text, Table 3). $E$, Amplitude distribution of noise (squares) and noise-contaminated PSP (circles) derived from the 1500 sweeps during the period indicated by the horizontal bar in $D$. Bin width, $50 \mu \mathrm{V}$.

which the null hypothesis was rejected. Therefore, the fluctuations in the noise-contaminated PSP amplitude were not due entirely to variations in background noise, and there must have been true fluctuations in the PSP amplitude despite consistent spiking in the presynaptic neuron.

From the records of each of the 16 synaptic connections, we selected a region of at least 500 sweeps over which the PSP amplitude was "stationary," as defined by the criterion that the average PSP amplitude of consecutive, 100-sweep epochs varied by less than $\pm 10 \%$ of the average PSP amplitude of all the available sweeps. (Four synaptic connections failed to provide a region of 500 sweeps meeting this criterion and were excluded from further analysis.) Noise and noise-contaminated PSP amplitude distributions were constructed using all the sweeps from 
Table 4. Parameters of noise and noise-contaminated PSP distributions

\begin{tabular}{ccccll} 
PSP & $\begin{array}{l}\text { Number of } \\
\text { sweeps }\end{array}$ & $\begin{array}{l}\text { Noise SD } \\
(\mu \mathrm{V})\end{array}$ & $\begin{array}{l}\text { PSP }+ \\
\text { noise } \\
\text { mean }(\mu \mathrm{V})\end{array}$ & $\begin{array}{l}\text { PSP }+ \\
\text { noise } \\
\text { SD }(\mu \mathrm{V})\end{array}$ & $\mathrm{CV}$ \\
\hline 1 & 1000 & 92 & 333 & 185 & 0.48 \\
2 & 600 & 82 & 314 & 203 & 0.59 \\
3 & 1500 & 99 & 1501 & 387 & 0.25 \\
4 & 500 & 129 & 458 & 229 & 0.41 \\
5 & 1200 & 114 & 274 & 154 & 0.38 \\
6 & 700 & 130 & 488 & 197 & 0.30 \\
7 & 500 & 163 & 99 & 171 & 0.54 \\
9 & 500 & 114 & 56 & 141 & 1.50 \\
11 & 500 & 107 & 242 & 172 & 0.56 \\
12 & 800 & 98 & 553 & 286 & 0.49 \\
13 & 800 & 114 & 178 & 153 & 0.57 \\
14 & 800 & 90 & 179 & 128 & 0.51
\end{tabular}

The PSP identification numbers correspond to those used in Table 3. Four PSPs are missing because they did not have a "stationary" period of at least 500 sweeps (sec text). "Number of swecps" refers to the number of "stationary" swecps (sce text) for each synaptic connection, not the total number of sweeps available. CV

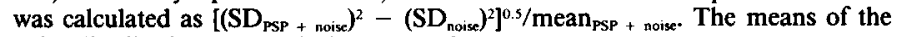
noise distributions were within $12 \mu \mathrm{V}$ of 0 .

the stationary periods. An example is shown in Figure $8 E$, and the distribution parameters for all 12 synaptic connections are given in Table 4. We also calculated, for each synaptic connection, the coefficient of variation (CV) of PSP amplitude after subtraction of the noise variance (Table 4).

\section{Discussion}

Using dual intracellular impalements in layer $2 / 3$ of the rat visual cortex, we have shown that PSPs can be recorded from individual neurons following action potentials evoked in single neurons nearby. Before discussing the properties of these PSPs in detail, we will present our reasons for believing that they represented excitatory monosynaptic transmission between pyramidal cells.

We are confident that both presynaptic and postsynaptic neurons were pyramidal. First, pyramidal cells represent $85 \%$ of the neurons in layer $2 / 3$ of the rat visual cortex (Peters et al., 1985). Second, the electrophysiological properties of the impaled neurons were very similar to those obtained in a previous study of layer $2 / 3$ of the rat visual cortex in which the identity of the pyramidal neurons was confirmed by intracellular staining with HRP (Mason and Larkman, 1990). Third, all of the neurons that we stained by intracellular iontophoresis of biocytin (over $1 / 3$ of the total) had pyramidal morphology.

The short latencies of the PSPs (only 3 had latencies greater than $2.0 \mathrm{msec}$ ) suggest that they were mediated by monosynaptic connections. The latency distribution was similar to that obtained for local excitatory connections (believed to be monosynaptic) in the motor cortex (Kang et al., 1988), the cingulate and sensorimotor cortex (Thomson et al., 1988), and the CA3 region of hippocampus (Miles and Wong, 1986). In the hippocampus, polysynaptic EPSPs have latencies of at least $8 \mathrm{msec}$, and the minimum latency recorded for a disynaptic IPSP is 2.4 msec (Miles and Wong, 1984, 1986).

In agreement with previous studies of cortical slices in vitro, the pyramidal cells in which PSPs were recorded had resting potentials of about $-75 \mathrm{mV}$. At this potential, IPSPs may be reversed in polarity, appearing as depolarizing potentials (Scholfield, 1978; Connors et al., 1982; Avoli and Olivier, 1989). However, for nearly $1 / 3$ of the PSPs, we depolarized the postsynaptic neuron to around action potential threshold, and in all cases, the PSPs remained depolarizing. Therefore, we believe that the PSPs described here were EPSPs and not reversed IPSPs. This conclusion is consistent with the results of a study of synaptic interactions between neurons of the rat visual cortex in cell culture (Huettner and Baughman, 1988). These authors found that corticollicular pyramidal cells, identified by prior retrograde labeling, evoked only excitatory synaptic potentials in postsynaptic neurons.

We did not encounter any inhibitory synaptic interactions in the present study. Given that the presynaptic cells were pyramidal, and assuming that pyramidal cells make only excitatory synapses on their postsynaptic targets, then IPSPs would have been seen only if interposed inhibitory neurons were brought to firing threshold by single action potentials in individual presynaptic pyramidal cells. Although this has been demonstrated in the CA3 region of the hippocampus (Miles and Wong, 1984; Miles, 1989), whether it can occur in the neocortex is not known.

\section{PSP amplitude}

The amplitudes of the averaged PSPs recorded in this study varied from 0.05 to $2.08 \mathrm{mV}$. This is probably an underestimate of the true range because of sampling limitations and because PSPs smaller than about $0.03 \mathrm{mV}$ would have gone undetected. There was no correlation between PSP amplitude and any of the electrophysiological properties of the postsynaptic cells, so the variation in PSP amplitude was probably due to factors such as different numbers of synaptic contacts between the neurons, differences in postsynaptic receptors, and the statistics of transmitter release at the synapses. Thomson et al. (1988) reported a very similar range of amplitudes $(0.08-2.3 \mathrm{mV})$ for singleaxon EPSPs in the cingulate and sensorimotor cortex and also found no correlation with the input resistance of the postsynaptic cells. Although the amplitudes of the PSPs recorded in the present study were very variable, it is clear that many such inputs would have becn required to raise a postsynaptic cell from its resting potential in the in vitro slice (about $-75 \mathrm{mV}$ ) to firing threshold (about $-55 \mathrm{mV}$ ). However, the functional significance of this result is unclear, owing to the many uncertainties about the factors that determine synaptic efficacy during normal neuronal activity in the awake animal.

In other regions of the CNS, the depolarization at the soma due to a single quantum of transmitter is in the range of $0.1-$ $0.4 \mathrm{mV}$ (Jack et al., 1981; McNaughton et al., 1981; Miles and Wong, 1986; Walmsley et al., 1987; Harrison et al., 1989; Sayer et al., 1989, 1990). Assuming that synaptic transmission in the visual cortex is quantal, that quantal size lies in a similar range, and that synaptic boutons can be equated with quanta (see Redman, 1990), the most simplistic argument suggests that between 5 and 20 boutons would be needed to produce the largest PSPs recorded in the present study. This figure is in reasonable agreement with anatomical estimates of the number of synaptic contacts made by a single pyramidal cell onto any other in the visual cortex (Martin, 1984; Kisvárday et al., 1986; Gabbott et al., 1987).

The amplitude of the PSPs fluctuated from sweep to sweep, showing that an invariant presynaptic event (i.e., an action potential) can give rise to a variable postsynaptic response. Similar results have been obtained for EPSPs in the spinal cord (e.g., 
Jack et al., 1981; Walmsley et al., 1988; Harrison et al., 1989) and hippocampus (Sayer et al., 1989, 1990). The CVs of the PSP amplitude distributions, after subtraction of the noise variance (median, 0.50 ; range, $0.25-1.50$ ), were mostly lower than those found at synaptic connections between individual CA3/ CAl cell pairs in the hippocampus (median, 0.76 ; range, $0.37-$ 1.02; Sayer et al., 1990).

\section{PSP time course}

Our ranges of values for normalized 10-90\% rise time and width at half amplitude overlapped those found previously for EPSPs in the cortex (Thomson et al., 1988) and hippocampus (Miles and Wong, 1986; Turner, 1988; Sayer et al., 1990), but particularly for $10-90 \%$ rise time, the mean values were less than those found previously.

The shape index plot (Fig. 3) suggests that the PSPs recorded in the present study originated at a range of electrotonic distances from the recording site, with the points closer to the origin representing the more proximal inputs. However, to quantify these distances, it would be necessary to assume that the PSPs were propagated passively along the dendrites and to know the time course of the synaptic current and the electrical geometry of the postsynaptic cell, information that is not yet available for neocortical pyramidal neurons (Stratford et al., 1989). The residual scatter of the points in the shape index plot may be due to spatial dispersion of the individual components contributing to the PSPs (Rall, 1967; Rall et al., 1967; Jack et al., 1971; Walmsley and Stuklis, 1989), but other factors such as variation in the synaptic-current time course (Walmsley and Stuklis, 1989), temporal dispersion of PSP components (Redman and Walmsley, 1983; Walmsley and Stuklis, 1989), and distortion by intrinsic membrane currents may also contribute. The existence of spatial or temporal dispersion is suggested by the presence of a "notch" on the rising phase for 3 of the PSPs.

The lack of a significant correlation between PSP amplitude and $10-90 \%$ rise time or width at half amplitude suggests that the size of the PSPs recorded at the soma was not determined primarily by the electrotonic distance from the soma of the postsynaptic sites. A similar lack of correlation was also reported for single-axon EPSPs in the cingulate and sensorimotor cortex (Thomson et al., 1988) and for group Ia afferent EPSPs in spinal motoneurons (Iansek and Redman, 1973; Harrison et al., 1989), where it has also been shown that the amplitude of individual quanta recorded at the soma are independent of the site of origin (Jack et al., 1981; Harrison et al., 1989). However, other studies of group Ia afferents to spinal motoneurons have reported a weak, negative correlation between EPSP amplitude and rise time (Mendell and Henneman, 1971; Mendell and Weiner, 1976).

PSPs decayed with an approximately exponential time course, with time constants that were correlated with the membrane time constants of the cells in which they were recorded, and there was no overall correlation between the time constant of PSP decay and the membrane potential of the postsynaptic cell. Although these findings suggest that PSP decay was shaped primarily by passive membrane properties, all PSPs were recorded at relatively negative membrane potentials, and for any single PSP, we did not measure the time constant of decay at different membrane potentials. Furthermore, the time constant of PSP decay was nearly always greater than the time constant of decay following injected current pulses, a phenomenon that could be due to a prolonged synaptic current or to the involvement of active, intrinsic membrane currents.
In agreement with the results of the present study, Sayer et al. (1990) reported that nearly all EPSPs in CA1 cells (evoked by action potentials in single CA3 cells) decayed exponentially, though it was not stated whether the time constant of EPSP decay was longer than the membrane time constant. In contrast, Thomson et al. (1988) found that the shape of EPSP decay in neurons of the cingulate and sensorimotor cortex varied greatly, not always being exponential, and was affected by changes in membrane potential. Changes in membrane potential had parallel effects upon the voltage decay following intracellular current injection, suggesting that intrinsic membrane currents were involved. Many studies have demonstrated that voltage-sensitive currents are present in dendrites and can influence the shape of PSPs (e.g., Wong et al., 1979; Stafstrom et al., 1985; Clements et al., 1986; Miles and Wong, 1986; Chan et al., 1989; Gruol et al., 1989; Sutor and Hablitz, 1989a). In addition, there is evidence that NMDA-mediated currents contribute to EPSPs in the neocortex and can prolong their falling phases (Thomson, 1986; Artola and Singer, 1987; Huettner and Baughman, 1988; Jones and Baughman, 1988; Sutor and Hablitz, 1989b).

In summary, though we cannot say whether active membrane currents affected the time course of the PSPs recorded in the present study, it seems likely that they will influence the shapc of synaptic potentials during normal neuronal activity, at membrane potentials closer to firing threshold.

\section{Multiple PSPs recorded in the same neuron}

We found 6 examples where more than 1 presynaptic cell elicited PSPs in a single postsynaptic cell, thus demonstrating functional convergence of pyramidal cell connections. A high degree of convergence is expected from anatomical studies of the visual cortex because each pyramidal neuron receives of the order of $10^{4}$ excitatory synapses (Peters, 1987a), whereas the number of synapses made between a single pyramidal cell and any other individual pyramid is of the order of $10^{1}$ (Martin, 1984; Kisvárday et al., 1986; Gabbott et al., 1987).

The amplitudes of the multiple PSPs recorded in a single neuron were widely different from each other, in agreement with other studies of convergent inputs in the cingulate and sensorimotor cortex (Thomson et al., 1988), hippocampus (Sayer et al., 1990), and spinal cord (Mendell and Weiner, 1976). In the present study, statistical testing showed that the amplitudes of multiple PSPs recorded in a single cell were as different as the amplitudes of PSPs not sharing a common postsynaptic cell.

Of the 3 measures of PSP shape (10-90\% rise time, width at half amplitude, and time constant of decay), only the last was more similar for PSPs recorded in the same neuron than for PSPs not sharing a common postsynaptic cell. Although the result for time constant of decay is expected from the correlation between PSP decay time constant and membrane time constant (see above), it is surprising that the result for width at half amplitude was not significant. Perhaps this reflects the contribution of $10-90 \%$ rise time, which varied widely between PSPs recorded in the same cell.

In some cases, the shape indices of PSPs recorded in a single postsynaptic cell were sufficiently different as to span a large part of the shape index plot for the entire sample of PSPs. This suggests that different pyramidal neurons, lying within a very restricted region of the same cortical layer, can make synapses on different parts of the dendritic arbor of a single postsynaptic pyramidal cell nearby. This conjecture is consistent with the 
spread of local axon arbors over several cortical layers (see Fig. 7).

\section{Reciprocal connections}

We found 4 pairs of neurons that were connected reciprocally. Electrophysiological evidence suggested that both members of each pair were pyramidal cells, and in one case, this was confirmed by intracellular staining. Although reciprocal synaptic interactions between a pyramidal cell and an inhibitory interneuron have been found in the hippocampus (Knowles and Schwartzkroin, 1981), reciprocal connections between pairs of pyramidal cells have not been described previously. The most conventional explanation for the phenomenon is that each pyramidal cell made chemical axodendritic synapses with the other though we cannot exclude the possibility of dendrodendritic interactions. Reciprocal, chemically mediated synaptic connections between dendrites have been described in several regions of the nervous system (Dowling, 1968; Harding, 1971; Reese and Shepherd, 1972; White, 1972), though there is no evidence for their existence in the neocortex. Of course, the reciprocal excitatory connections described in the present study would tend to give rise to positive feedback between the 2 pyramidal neurons. Howcver, the small amplitude of the PSPs suggests that this effect is likely to be weak relative to the total synaptic input to each cell.

\section{Connectivity and functional implications}

We found 48 synaptic connections out of a possible 549 , equivalent to a connection probability of approximately 0.09 . This must be regarded as a minimum estimate because we may have missed connections with very small amplitudes, and some axon pathways mediating local connections may have been cut by the slicing procedure. In the cingulate and sensorimotor cortex, Thomson et al. (1988) found a connection probability between layer $3 / 4$ and layer 3 neurons of about 0.04 . In the hippocampus, connection probabilities of about 0.02 and 0.06 have been obtained for local CA3 cell pairs and for CA3/CA1 cell pairs, respectively (Miles and Wong, 1986; Sayer et al., 1990). Howcver, due to differences in cxpcrimental proccdurcs, such comparisons must be made with caution.

Local excitatory connections, perhaps particularly the reciprocal connections, could serve to synchronize activity in cells with similar receptive-field properties or output targets. In the cat visual cortex, there is evidence that axon collaterals of pyramidal neurons make excitatory connections onto other pyramids with similar receptive-field properties (Kisvárday et al., 1986; Ts'o et al., 1986; Gabbott et al., 1987; Gilbert and Wiesel, 1989). Although there is little evidence for ocular dominance and orientation columns, the rodent visual cortex is organized retinotopically, and the neurons have receptive-field properties similar to those of more "visual" animals (Dräger, 1975; Tiao and Blakemore, 1976; Mangini and Pearlman, 1980; Burne et al., 1984). Anatomical studies of the rat visual cortex have revealed the existence of cortical modules, vertically organized around clusters of apical dendrites of pyramidal cells (Peters and Kara, 1987). The mean center-to-center spacing of the clusters is about $60 \mu \mathrm{m}$. Because we found synaptic connections when the horizontal separation between impalement sites was much greater than this value, it is unlikely that connections are restricted to pyramidal cells within the same cortical module.

The probability and strength of excitatory connections between pyramidal cells have implications for the generation and spread of synchronous activity in the neocortex during, for example, epileptic behavior. Horizontal spread of neocortical activity is normally strongly constrained by inhibitory processes, but even slight suppression of GABA-mediated inhibition greatly increases the spread of excitation (Chagnac-Amitai and Connors, 1989a). However, during epileptiform events under these conditions, most subclasses of pyramidal cells show predominantly inhibitory responses (Chagnac-Amitai and Connors, 1989 a,b). Only a population of intrinsically bursting pyramidal cells, found in the middle cortical layers (McCormick et al., 1985; Agmon and Connors, 1989; Mason and Larkman, 1990), exhibit persistent excitation (Chagnac-Amitai and Connors, $1989 \mathrm{~b}$ ). It has been suggested that these particular neurons form an interconnected network capable of initiating widespread synchronous activity under conditions of reduced inhibition (Gutnick et al., 1982; Chagnac-Amitai and Connors, 1989b). Therefore, it would be of great interest to explore the pattern and strength of connections between the various subclasses of pyramidal cells, particularly the intrinsically bursting type, using dual intracellular recording.

\section{References}

Agmon A, Connors BW (1989) Repetitive burst-firing neurons in the deep layers of mouse somatosensory cortex. Neurosci Lett 99:137141.

Artola A, Singer W (1987) Long-term potentiation and NMDA receptors in rat visual cortex. Nature 330:649-652.

Avoli M, Olivier A (1989) Electrophysiological properties and synaptic responses in the deep layers of the human epileptogenic neocortex in vitro. J Neurophysiol 61:589-606.

Baughman RW, Gilbert CD (1981) Aspartate and glutamate as possible neurotransmitters in the visual cortex. J Neurosci 1:427-439.

Bennett MVL (1977) Electrical transmission: a functional analysis and comparison to chemical transmission. In: Handbook of physiology, Sec 1, Vol 1, Cellular biology of neurons, Pt 1 (Kandel ER, ed), pp 357-416. Baltimore: Williams and Wilkins.

Burne RA, Parnavelas JG, Lin C-S (1984) Response properties of neurons in the visual cortex of the rat. Exp Brain Res 53:374-383.

Chagnac-Amitai Y, Connors BW (1989a) Horizontal spread of synchronized activity in neocortex and its control by GABA-mediated inhibition. J Neurophysiol 61:747-758.

Chagnac-Amitai Y, Connors BW (1989b) Synchronized excitation and inhibition driven by intrinsically bursting neurons in neocortex. $J$ Neurophysiol 62:1149-1162.

Chan CY, Hounsgaard J, Midtgaard J (1989) Excitatory synaptic responses in turtle cerebellar Purkinje cells. J Physiol (Lond) 409:143156.

Clements JD, Nelson PG, Redman SJ (1986) Intracellular tetraethylammonium ions enhance group Ia excitatory post-synaptic potentials evoked in cat motoneurones. J Physiol (Lond) 377:267-282.

Connors BW, Gutnick MJ, Prince DA (1982) Electrophysiological properties of neocortical neurons in vitro. J Neurophysiol 48:13021320.

Connors BW, Benardo LS, Prince DA (1983) Coupling between neurons of the developing rat neocortex. J Neurosci 3:773-782.

Dori I, Petrou M, Parnavelas JG (1989) Excitatory transmitter amino acid-containing neurons in the rat visual cortex: a light and electron microscopic immunocytochemical study. J Comp Neurol 290:169184.

Dowling JE (1968) Synaptic organization of the frog retina: an electron microscopic analysis comparing the retinas of frogs and primates. Proc R Soc Lond [Biol] 170:205-228.

Dräger UC (1975) Receptive fields of single cells and topography in mouse visual cortex. J Comp Neurol 160:269-290.

Elhanany E, White EL (1990) Intrinsic circuitry: synapses involving the local axon collaterals of corticocortical projection neurons in the mouse primary somatosensory cortex. J Comp Neurol 291:43-54.

Feldman ML (1984) Morphology of the neocortical pyramidal neuron. In: Cerebral cortex, Vol 1 (Peters A, Jones EG, eds), pp 123-200. New York: Plenum. 
Ferster D, Lindström S (1985) Synaptic excitation of neurones in area 17 of the cat by intracortical axon collaterals of cortico-geniculate cells. J Physiol (Lond) 367:233-252.

Gabbott PLA, Martin KAC, Whitteridge D (1987) Connections between pyramidal neurons in layer 5 of cat visual cortex (area 17). J Comp Neurol 259:364-381.

Ghosh S, Porter R (1988) Morphology of pyramidal neurones in monkey cortex and the synaptic actions of their intracortical collaterals. J Physiol (Lond) 400:593-615.

Gilbert CD, Wiesel TN (1983) Clustered intrinsic connections in cat visual cortex. J Neurosci 3:1116-1133.

Gilbert CD, Wiesel TN (1989) Columnar specificity of intrinsic horizontal and corticocortical connections in cat visual cortex. J Neurosci 9:2432-2442.

Gruol DL, Dionne VE, Yool AJ (1989) Multiple voltage-sensitive $\mathrm{K}^{+}$ channels regulate dendritic excitability in cerebellar Purkinje neurons. Neurosci Lett 97:97-102.

Gutnick MJ, Connors BW, Prince DA (1982) Mechanisms of neocortical epileptogenesis in vitro. J Neurophysiol 48:1321-1335.

Harding BN (1971) Dendro-dendritic synapses, including reciprocal synapses, in the ventro-lateral nucleus of the monkey thalamus. Brain Res 34:181-185.

Harrison PJ, Jack JJB, Kullmann DM (1989) Monosynaptic EPSPs in cat lumbosacral motoneurones from group Ia afferents and fibres descending in the spinal cord. J Physiol (Lond) 412:43-63.

Horikawa K, Armstrong WE (1988) A versatile means of intracellular labeling: injection of biocytin and its detection with avidin conjugates. J Neurosci Meth 25:1-11.

Huettner JE, Baughman RW (1988) The pharmacology of synapses formed by identified corticocollicular neurons in primary cultures of rat visual cortex. J Neurosci 8:160-175.

Iansek R, Redman SJ (1973) The amplitude, time course and charge of unitary excitatory post-synaptic potentials evoked in spinal motoneurone dendrites. J Physiol (Lond) 234:665-688.

Jack JJB, Miller S, Porter R, Redman SJ (1971) The time course of minimal excitatory post-synaptic potentials evoked in spinal motoneurones by group Ia afferent fibres. J Physiol (Lond) 215:353-380.

Jack JJB, Redman SJ, Wong K (1981) The components of synaptic potentials evoked in cat spinal motoneurones by impulses in single group Ia afferents. J Physiol (Lond) 321:65-96.

Jones KA, Baughman RW (1988) NMDA- and non-NMDA-receptor components of excitatory synaptic potentials recorded from cells in layer $\mathrm{V}$ of rat visual cortex. J Neurosci 8:3522-3534.

Kang Y, Endo K, Araki T (1988) Excitatory synaptic actions between pairs of neighboring pyramidal tract cells in the motor cortex. J Neurophysiol 59:636-647.

Kisvárday ZF, Martin KAC, Freund TF, Maglóczky Zs, Whitteridge D, Somogyi P (1986) Synaptic targets of HRP-filled layer III pyramidal cells in the cat striate cortex. Exp Brain Res 64:541-552.

Knowles WD, Schwartzkroin PA (1981) Local circuit synaptic interactions in hippocampal brain slices. J Neurosci 1:318-322.

Komatsu Y, Nakajima S, Toyama K, Fetz E (1988) Intracortical conncctivity revcalcd by spike-triggered avcraging in slicc preparations of cat visual cortex. Brain Res 442:359-362.

Larkman AU, Mason A (1990) Correlations between morphology and electrophysiology of pyramidal neurons in slices of rat visual cortex. 1. Establishment of cell classes. J Neurosci 10:1407-1414.

Larkman AU, Mason A, Blakemore C (1988) The in vitro slice preparation for combined morphological and electrophysiological studies of rat visual cortex. Neurosci Res 6:1-19.

MacVicar BA, Dudek FE (1980) Local synaptic circuits in rat hippocampus: interactions between pyramidal cells. Brain Res 184:220 223.

Mangini NJ, Pearlman AL (1980) Laminar distribution of receptive field properties in the primary visual cortex of the mouse. J Comp Neurol 193:203-222.

Martin KAC (1984) Neuronal circuits in cat striate cortex. In: Cerebral cortex, Vol 2 (Jones EG, Peters A, eds), pp 241-284. New York: Plenum.

Martin KAC, Whitteridge D (1984) Form, function and intracortical projections of spiny neurones in the striate visual cortex of the cat. J Physiol (Lond) 353:463-504.

Mason A, Larkman AU (1990) Correlations between morphology and electrophysiology of pyramidal neurons in slices of rat visual cortex. 2. Electrophysiology. J Neurosci 10:1415-1428.
Mason AJR, Nicoll A, Stratford KJ, Blakemore C (1989) Synaptic transmission between individual neurons in rat visual cortex. Soc Neurosci Abstr 15:257.

McCormick DA, Connors BW, Lighthall JW, Prince DA (1985) Comparative electrophysiology of pyramidal and sparsely spiny stellate neurons of the neocortex. J Neurophysiol 54:782-806.

McGuire BA, Hornung J-P, Gilbert CD, Weisel TN (1984) Patterns of synaptic input to layer 4 of cat striate cortex. J Neurosci 4:30213033.

McNaughton BL, Barnes CA, Andersen P (1981) Synaptic efficacy and EPSP summation in granule cells of rat fascia dentata studied in vitro. J Neurophysiol 46:952-966.

Mendell LM, Henneman E (1971) Terminals of single Ia fibers: location, density, and distribution within a pool of 300 homonymous motoneurons. J Neurophysiol 34:171-187.

Mendell LM, Weiner R (1976) Analysis of pairs of individual IaE.P.S.P.s in single motoneurones. J Physiol (Lond) 255:8 1-104.

Miles R (1989) Synaptic excitation of CA3 inhibitory neurones by single pyramidal cells in the guinea-pig hippocampus in vitro. J Physiol (Lond) 417:96P.

Miles R, Wong RKS (1984) Unitary inhibitory synaptic potentials in the guinea-pig hippocampus in vitro. J Physiol (Lond) 356:97-113.

Miles R, Wong RKS (1986) Excitatory synaptic interactions between CA3 neurones in the guinea pig hippocampus. J Physiol (Lond) 373: $397-418$.

Peters A (1987a) Number of neurons and synapses in primary visual cortex. In: Cerebral cortex, Vol 6 (Jones EG, Peters A, eds), pp 267294. New York: Plenum.

Peters A (1987b) Synaptic specificity in the cerebral cortex. In: Synaptic function (Edelman GM, Gall WE, Cowan WM, eds), pp 373397. New York: Wiley.

Peters A, Kara DA (1985) The neuronal composition of rat visual cortex. I. The pyramidal cells. J Comp Neurol 234:218-241.

Peters A, Kara DA (1987) The neuronal composition of rat visual cortex. IV. The organization of pyramidal cells. J Comp Neurol 260: 573-590.

Peters A, Kara DA, Harriman KM (1985) The neuronal composition of area 17 of rat visual cortex. III. Numerical considerations. J Comp Neurol 238:263-274.

Rall W (1967) Distinguishing theoretical synaptic potentials computed for different soma-dendritic distributions of synaptic input. J Neurophysiol 30:1138-1168.

Rall W (1969) Time constants and electrotonic length of membrane cylinders and neurons. Biophys J 9:1483-1508.

Rall W, Burke RE, Smith TG, Nelson PG, Frank K (1967) Dendritic location of synapses and possible mechanisms for the monosynaptic EPSP in motoneurons. J Neurophysiol 30:1169-1193.

Redman S (1990) Quantal analysis of synaptic potentials in neurons of the central nervous system. Physiol Rev 70:165-198.

Redman S, Walmsley B (1983) The time course of synaptic potentials evoked in cat spinal motoneurones at identified group Ia synapses. J Physiol (Lond) 343:117-133.

Recsc TS, Shepherd GM (1972) Dendro-dendritic synapses in the central nervous system. In: Structure and function of synapses (Pappas GD, Purpura DP, eds), pp 121-136. New York: Raven.

Sayer RJ, Redman SJ, Andersen P (1989) Amplitude fluctuations in small EPSPs recorded from CA1 pyramidal cells in the guinea pig hippocampal slice. J Neurosci 9:840-850.

Sayer RJ, Friedlander MJ, Redman SJ (1990) The time course and amplitude of EPSPs evoked at synapses between pairs of CA3/CA1 neurons in the hippocampal slice. J Neurosci 10:826-836.

Scholfield CN (1978) A depolarizing inhibitory potential in neurones of the olfactory cortex in vitro. J Physiol (Lond) 275:547-557.

Sloper JJ (1971) Dendro-dendritic synapses in the primate motor cortex. Brain Res 34:186-192.

Sloper JJ (1972) Gap junctions between dendrites in the primate neocortex. Brain Res 44:641-646.

Stafstrom CE, Schwindt PC, Chubb MC, Crill WE (1985) Properties of persistent sodium conductance and calcium conductance of layer $V$ neurons from cat sensorimotor cortex in vitro. J Neurophysiol 53: 153-170.

Stefanis C, Jasper H (1964) Intracellular microelectrode studies of antidromic responses in cortical pyramidal tract neurons. J Neurophysiol 27:828-854.

Stratford KJ, Mason AJR, Larkman AU, Major G, Jack JJB (1989) 
The modelling of pyramidal neurones in the visual cortex. In: The computing neurone (Durbin R, Miall C, Mitchison G, eds), pp 296321. New York: Addison Wesley.

Streit P (1984) Glutamate and aspartate as transmitter candidates for systems of the cerebral cortex. In: Cerebral cortex, Vol 2 (Jones EG, Peters A, eds), pp 119-143. New York: Plenum.

Sutor B, Hablitz JJ (1989a) EPSPs in rat neocortical neurons in vitro I. Electrophysiological evidence for two distinct EPSPs. J Neurophysiol 61:607-620.

Sutor B, Hablitz JJ (1989b) EPSPs in rat neocortical neurons in vitro II. Involvement of $N$-methyl-D-aspartate receptors in the generation of EPSPs. J Neurophysiol 61:621-634.

Takahashi K, Kubota K, Uno M (1967) Recurrent facilitation in cat pyramidal tract cells. J Neurophysiol 30:22-34.

Thomson AM (1986) A magnesium-sensitive post-synaptic potential in rat cerebral cortex resembles neuronal responses to $N$-methylaspartate. J Physiol (Lond) 370:531-549.

Thomson AM, Girdlestone D, West DC (1988) Voltage-dependent currents prolong single-axon postsynaptic potentials in layer III pyramidal neurons in rat neocortical slices. J Neurophysiol 60:18961907.

Thomson AM, Girdlestone D, West DC (1989) A local circuit neocortical synapse that operates via both NMDA and non-NMDA receptors. Br J Pharmacol 96:406-408.

Tiao Y-C, Blakemore C (1976) Functional organization in the visual cortex of the golden hamster. J Comp Neurol 168:459-482.
Ts'o DY, Gilbert CD, Wiesel TN (1986) Relationships between horizontal interactions and functional architecture in cat striate cortex as revealed by cross-correlation analysis. J Neurosci 6:1160-1170.

Turner DA (1988) Waveform and amplitude characteristics of evoked responses to dendritic stimulation of CA1 guinea-pig pyramidal cells. J Physiol (Lond) 395:419-439.

Walmsley B,Stuklis R (1989) Effects of spatial and temporal dispersion of synaptic input on the time course of synaptic potentials. J Neurophysiol 61:681-687.

Walmsley B, Edwards FR, Tracey DJ (1987) The probabilistic nature of synaptic transmission at a mammalian central synapse. J Neurosci 7:1037-1046.

Walmsley B, Edwards FR, Tracey DJ (1988) Non-uniform release probabilities underlie quantal synaptic transmission at a mammalian excitatory central synapse. J Neurophysiol 60:889-908.

White EL (1972) Synaptic organization in the olfactory glomerulus of the mouse. Brain Res 37:69-80.

White EL, Keller A (1987) Intrinsic circuitry involving the local axon collaterals of corticothalamic projection cells in mouse SmI cortex. J Comp Neurol 262:13-26.

Winfield DA, Brooke RNL, Sloper JJ, Powell TPS (1981) A combined Golgi-electron microscopic study of the synapses made by the proximal axon and recurrent collaterals of a pyramidal cell in the somatic sensory cortex of the monkey. Neuroscience 6:1217-1230.

Wong RKS, Prince DA, Basbaum AI (1979) Intradendritic recordings from hippocampal neurons. Proc Natl Acad Sci USA 76:986-990. 